\title{
Naturally occurring chronic gastritis and $C$ pylori infection in the Rhesus monkey: a potential model for gastritis in man
}

\author{
A BASKERVILLE AND D G NEWELL
}

From the Experimental Pathology Laboratory, PHLS, Centre for Applied Microbiology and Research, Porton Down, Salisbury, Wilts

SUMMARY Histological examination of the stomachs of Rhesus monkeys at autopsy showed chronic gastritis in a high proportion of all ages. Lesions consisted of mild to heavy infiltration of the lamina propria by lymphocytes, plasma cells, and histiocytes. The antrum was most consistently affected, but lesions were also present in the fundus and pylorus. Gastric Campylobacter-like organisms (GCLO) apparently identical to human $C$ pylori were cultured and/or detected immunohistologically in several animals. Electron microscopy showed the spiral bacteria on the epithelial surface and in gastric pits. They did not penetrate the cells but were intimately attached to the apical plasma membrane and caused loss of microvilli. Antibodies to $C$ pylori were detected in serum of the monkeys by ELISA. The immunospecificity of this antibody response was confirmed by Western blotting techniques. A small number of cynomolgus monkeys examined had gastritis, which may also be associated with the presence of $C$ pylori. Baboons did not have gastritis, nor was $C$ pylori cultured from their stomachs. The study indicates that the Rhesus monkey has a naturally occurring gastritis associated with $C$ pylori infection and may therefore be a suitable experimental animal for the human disease.

In recent years a number of studies of gastritis using gastroscopy and biopsy techniques have provided strong evidence of an association between infection of the gastric mucosa with $C$ pylori, chronic gastritis confirmed histologically and even peptic ulceration. ${ }^{1-5}$ This is an extremely significant finding for if $C$ pylori is a common cause of gastritis, as is being postulated, then it should be susceptible to antibiotic treatment and remission of symptoms might be readily achieved. As with many human diseases, progress in the understanding of $C$ pylori gastritis would be immeasurably increased if there were an animal model of the infection for experimental use. In particular, the pathogenesis of the lesions might be studied, immune mechanisms elucidated, and therapy with various antibiotics and other drugs could be evaluated. Because no animal model

Address for correspondence: Dr A Baskerville, Public Health Laboratory Service, Centre for Applied Microbiology and Research, Porton Down, Salisbury, Wiltshire SP4 0JG.

Received for publication 13 October 1987 presently exists a search was undertaken for a relevant system in non-human primate species, using Rhesus monkeys, baboons, and cynomolgus monkeys which came to autopsy for other reasons.

\section{Methods}

ANIMALS

The Rhesus monkeys (Macaca mulatta) examined came from a closed breeding colony in the United Kingdom. They were kept in a large outdoor compound with adjacent indoor accommodation and lived and bred under harem conditions. The colony was divided into a number of groups, each group consisting of two adult males, 20 females and their progeny. They were fed a mixed diet of commercial pellets, fruit, and bread and allowed water ad libitum. Ten animals of both sexes were used in the survey and ranged in age from two to eight years. An additional male was also studied. This had been caught in Africa and kept in the United Kingdom for at least 15 years. 
Ten baboons (Papio spp) were also examined. These were caught in the wild in Africa and imported into the United Kingdom. For this reason their exact age was unknown but all were young adults of either sex weighing $4-7 \mathrm{~kg}$. They were caged singly, fed fruit with a commercial pelletted diet and allowed water ad libitum.

Five adult cynomolgus monkeys (Macaca fascicularis) were examined. These were bred in the United Kingdom under harem colony conditions.

All animals were first anaesthetised by intramuscular injection of ketamine hydrochloride ('Vetalar', Parke Davis, Pontypool, Gwent, UK), a blood sample was taken for serum and they were then killed by intravenous injection of sodium pentobarbitone.

\section{PATHOLOGY}

Necropsy was carried out immediately after death and the distal oesophagus and duodenum ligated before removal of the stomach. The stomach was opened longitudinally along the entire length of the greater curvature and after inspection of the mucosa numerous portions of the cardia, body, antrum, and pylorus were taken for histopathology and electron microscopy. The duodenum was also fixed for histology. Specimens of the body and antrum were taken for bacterial culture and some samples snap frozen in liquid nitrogen for immunohistology. For histopathological studies tissues were fixed in $10 \%$ buffered neutral formalin and processed by standard methods, embedded in paraffin wax and sections cut at $5 \mu \mathrm{m}$. Sections were stained by haematoxylin and eosin and selected sections were stained by the periodic acid - Schiff (PAS) method, by Gordon and Sweet's technique for reticulin and by WarthinStarry. For electron microscopy samples of gastric mucosa were immediately fixed in $4 \%$ phosphatebuffered glutaraldehyde $(\mathrm{pH} 7 \cdot 2)$ at $4^{\circ} \mathrm{C}$ for two hours, post fixed in $1 \%$ osmium tetroxide for two hours, dehydrated, and embedded in Araldite. Semithin sections of the blocks were cut with glass knives at $1 \mu \mathrm{m}$ and stained with toluidine blue to identify suitable areas. Ultrathin sections were then cut using a diamond knife and stained with uranyl acetate and lead citrate.

\section{IMMUNOHISTOLOGY}

Six to $8 \mu \mathrm{m}$ cryostat sections were fixed in dry acetone at $-20^{\circ} \mathrm{C}$ for 10 minutes. Endogenous peroxidase was inactivated with $0.001 \%(\mathrm{v} / \mathrm{v})$ phenylhydrazine for 60 minutes. The sections were incubated with 1:100 dilution of purified mouse monoclonal antibody, CP1, directed against a species-specific surface protein of $C$ pylori ${ }^{6}$ Bound antibody was detected with goat antimouse IgG coupled to peroxidase. An unrelated antiguinea pig $\mathrm{T}$ cell monoclonal antibody, GPA (kindly supplied by B McBride), was used as a control. Bound peroxidase was visualised with the 3amino-9-ethylcarbazole substrate.

ISOLATION AND CHARACTERISATION OF

CAM PYLOBACTER-LIKE ORGANISMS

Post mortem gastric mucosa samples were smeared directly onto blood agar containing $5 \%$ defibrinated horse blood with Skirrow's antibiotics. ${ }^{7}$ Plates were cultured for up to five days at $37^{\circ} \mathrm{C}$ in a microaerophilic atmosphere. Gastric Campylobacter-like organisms were identified by morphology, positive catalase, and oxidase reactions and by the rapid hydrolysis of urea. ${ }^{8}$

\section{ANTIGEN PREPARATION}

An acid extractable surface material was prepared from $C$ pylori strain NCTC 11638 as previously described. ${ }^{9}$

\section{MICROELISA TECHNIQUE}

The concentration of anti- $C$ pylori antibodies was determined in sera from the Rhesus monkeys using an ELISA technique previously established for the detection of human anti- $C$ pylori antibodies, with an acid extractable material as the solid phase antigen. ${ }^{10}$ Because of the close phylogenic relationship between Rhesus monkey and man" bound Rhesus monkey IgG antibodies were detected with goat antihuman IgG coupled to peroxidase (Amersham International, UK). $\mathrm{OD}_{450}$ readings of over 0.3 were taken as positive sera. Baboon immunoglobulin did not appear to crossreact with this antihuman IgG antisera and were not therefore investigated.

\section{WESTERN BLOTTING TECHNIQUE}

Total protein profiles of the Rhesus monkey gastric Campylobacter-like organisms, strain 87008, were separated on a $10-25 \%$ gradient SDS-PAGE gel, electroblotted and incubated with Rhesus monkey sera as previously described. ${ }^{12}$ Bound antibodies were detected with goat antihuman IgG coupled to peroxidase (Bio-Rad Limited, UK). ${ }^{11}$

\section{Results}

The stomachs of 10 Rhesus monkeys from the colony were examined histopathologically together with that of one other wild-caught male Rhesus; stomachs from 10 baboons and five cynomolgus monkeys were also studied. The numbers having histological evidence of gastritis and those from which $C$ pylori was isolated or detected by immunohistochemistry are shown in the Table. Macroscopically no ulcers were found in any region and although the mucosa 
Table Presence of chronic gastritis and $\mathrm{C}$ pylori in nonhuman primates

\begin{tabular}{lllll}
\hline & & $\begin{array}{l}\text { Chronic } \\
\text { Sxamined } \\
\text { gastritis } \\
(n)\end{array}$ & $\begin{array}{l}\text { Cpyloriby } \\
\text { isolation } \\
(n)\end{array}$ & $\begin{array}{l}\text { Cpyloriby } \\
\text { immunohistology } \\
(n)\end{array}$ \\
\hline Rhesus & 11 & 8 & $2 / 7$ & $4 / 6$ \\
Baboon & 10 & 0 & $0 / 6$ & $\mathrm{ND}$ \\
Cynomolgus & 5 & 2 & $(0 / 1$ & $1 / 1$ \\
\hline
\end{tabular}

$\mathrm{ND}=$ not done

occasionally was redder in some areas than others this was shown histologically to be of no significance. Baboon stomachs often contained nematode worms.

The histopathological findings in the Rhesus monkeys were very consistent and varied mainly in degree. Three animals had no lesions, but in eight of 11 there was widespread chronic gastritis, with intense infiltration of the lamina propria by lymphocytes, plasma cells, and histiocytes. The infiltrate usually occupied the upper half of the mucosa but often also formed almost continuous cell sheets through the deeper portions, extending to the muscularis mucosae (Figs 1-3). There were no erosions and the surface epithelium was predominantly normal, although at some sites of intense inflammation it was of simple squamous type, basophilic, and lacking mucin. Polymorphonuclear leucocytes were only rarely found as occasional single cells. These were adjacent to pits or glands containing masses of bacteria. The chronic inflammatory infiltrate was most consistently present and densest in the antrum, but many foci and larger areas were also present in the cardia, body, pylorus, and duodenum of the majority of monkeys. Large lymphoid follicles, some with prominent germinal centres, occurred in most stomachs and these frequently extended into the submucosa. Where intense cellular infiltration was present in the body, parietal cell and chief cell portions of gastric glands had been lost locally and adjacent ones were atrophic or metaplastic (Figs 3, $4)$. There was considerable mitotic activity in many pits and glands in such areas and a great reduction in their PAS-positive mucin content. Intestinal metaplasia was rarely seen and then only focally. The metaplastic changes in pits and glands led mainly to their being lined by apparently undifferentiated columnar cells with basophilic cytoplasm. In a few older animals gland atrophy had been succeeded by fibrosis and an increase in histiocytes in the lamina propria.

Inflammatory cells were only rarely present in the gastric pits or in the lumen of glands in the body or antrum and cell damage was minimal. In some areas the surface, pits and glands contained large numbers

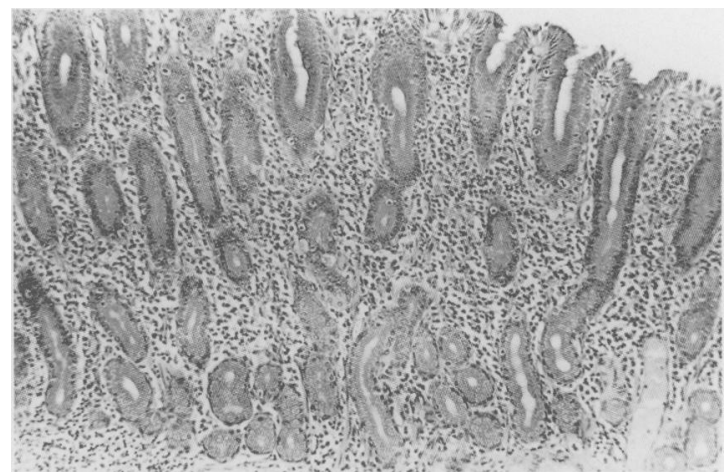

Fig. 1 Chronic gastritis, antrum, Rhesus money, showing diffuse cellular infiltration. $(H \& E)$.

of spiral bacteria which were visible in $\mathrm{H}$ and $\mathrm{E}$ stained sections, but more clearly demonstrable in Warthin-Starry preparations or in semithin plastic sections stained with toluidine blue. Immuno-

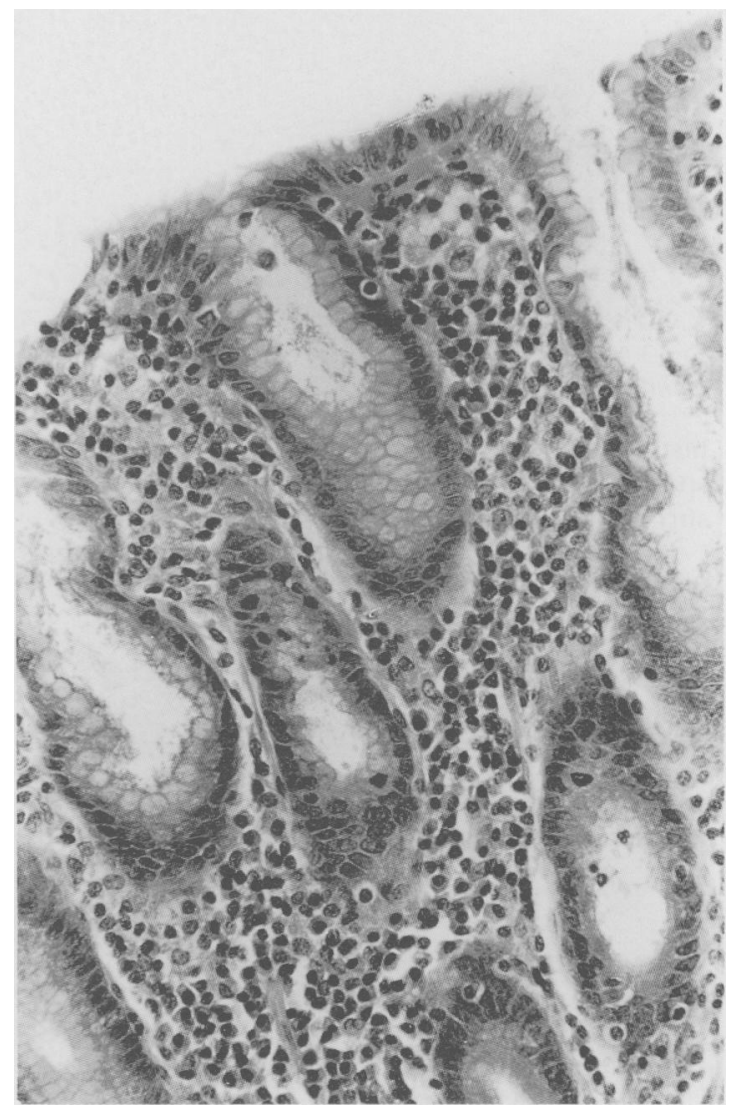

Fig. 2 Chronic gastritis, antrum. Intense infiltration by lymphocytes and plasma cells. Organisms are present on the epithelial surface of the pits. $(H \& E)$. 


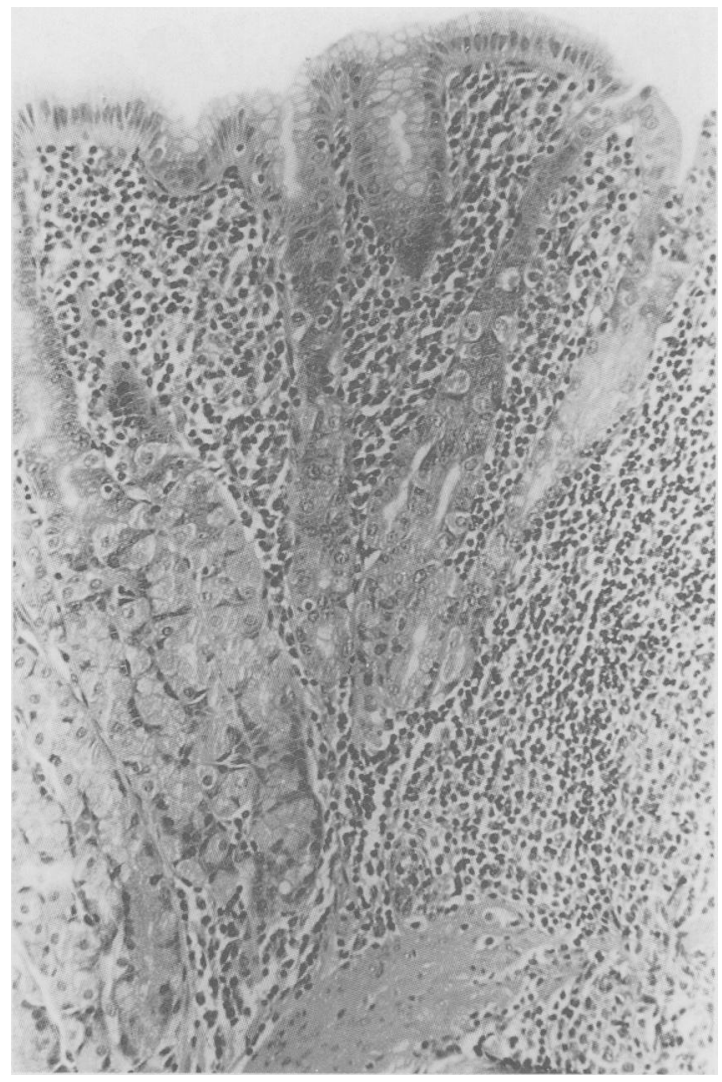

Fig. 3 Fundic mucosa. Extensive gastritis and loss of glands. $(H \& E)$.

histological studies, using an anti-C pylori species specific monoclonal antibody, showed that $C$ pylori surface antigen was present at these sites.

Electron microscopy revealed large numbers of spiral bacteria on the epithelial surface, in gastric pits

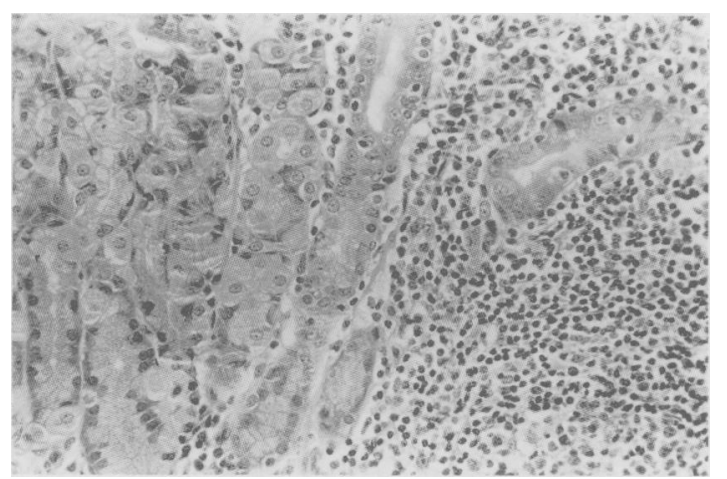

Fig. 4 Fundus, edge of area of inflammation and gland atrophy. Glands in centre and on right are undifferentiated. $(H \& E)$. and in the lumen of antral glands (Figs 5 and 6). The organisms had a similar morphology to that described for human $C$ pylori in gastric biopsies." Flagella were seen attached in gastric Campylobacter-like organisms sectioned favourably, but in others portions of flagella were visible in various planes. Many of the bacteria closest to the apical surface of the epithelial cells appeared to have formed close attachments to the plasma m 2 mbrane (Fig. 6) and at some sites the outer layer of bacterial wall and the cell membrane seemed to be fused. No particular region of the bacteria was consistently used; for many attachment was by one pole pushing into the cytoplasm to form a cup-like depression, for others almost the entire lateral surface was in intimate contact with the plasma membrane (Figs 5 and 6). There was no evidence to suggest attachment by a specialised process on the bacteria. An obvious and significant feature was the ablation of most microvilli from the cell surface where the gastric Campylobacter-like organisms were present (Figs 5 and 6). Phagocytosis of gastric Campylobacter-like organisms by inflammatory cells was not observed. The cellular infiltrates in the lamina propria were unremarkable by electron microscopy, but their identity as large and small lymphocytes and plasma cells was confirmed.

Gastric Campylobacter-like organisms were cultured from the gastric mucosa of only two of seven Rhesus monkeys tested even though immunohistology indicated the presence of gastric Campylobacter-like organisms in at least two further monkeys. Raised antibody levels to $C$ pylori acid extract antigen were detected in the serum of 13/23 Rhesus monkeys investigated by ELISA under the conditions described. These antibodies were directed against a number of gastric Campylobacter-like organisms bacterial proteins (Fig. 7). There was a significant variation in the specificity of the antibody response by the Rhesus monkeys. Only a $120 \mathrm{kDa}$ protein was consistently labelled by all positive sera. A $54 \mathrm{kDa}$ protein was labelled by most of the sera.

Gastritis was not present in any of the 10 baboon stomachs available. In three, however, there were occasional foci of lymphocytes and plasma cells and rarely a lymphoid follicle at the junction of mucosa and submucosa. In each case the animal had several nematodes in the stomach which were penetrating deep into the mucosa and had probably elicited the lymphoid response. The size and distribution of these small focal lesions allowed them to be readily distinguished from the gastritis seen in the Rhesus monkeys. Bacteriological examination was carried out in six of 10 baboons. Gastric Campylobacterlike organisms were not isolated from any baboon stomach, but $C$ jejuni was in two of six.

Histopathological examination of the five cyno- 


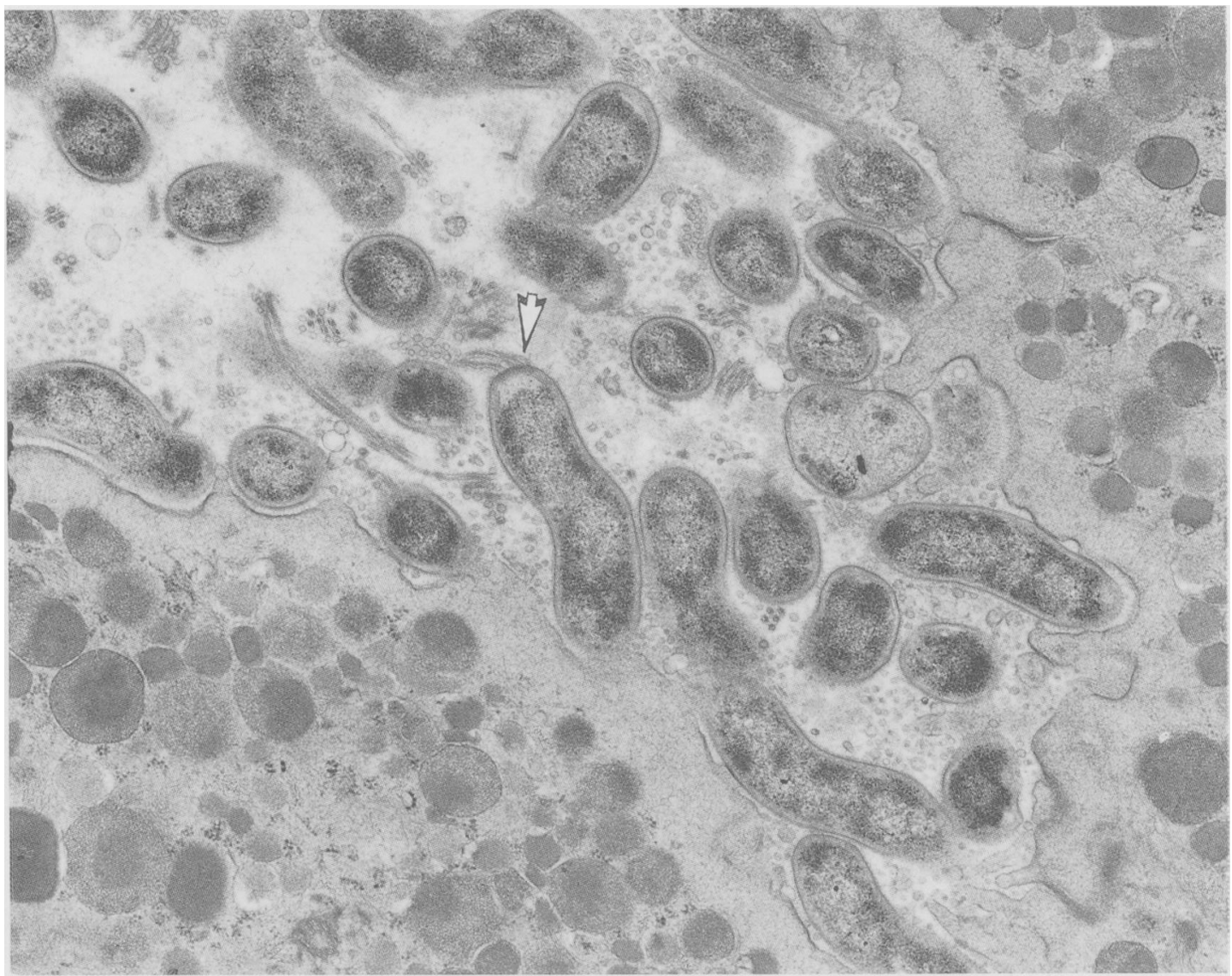

Fig. 5 Electron micrograph of antral pit epithelium, showing spiral bacteria in lumen and on cell surfaces. Attachment point of flagella to one organism can be seen (arrow).

molgus monkey stomachs showed extensive chronic gastritis of the type seen in the Rhesus in two of five animals. In this species too, the antrum and pylorus were more heavily involved than the fundus. Culture of organisms was attempted in only one of these but only $C$ jejuni was recovered. Immunohistology indicated very sparse and patchy colonisation of the crypts in the only monkey investigated with this technique.

\section{Discussion}

This study has identified for the first time the existence in Rhesus monkeys of chronic gastritis associated with infection by gastric Campylobacterlike organisms. The lesions are similar to those in man and it is therefore highly probable that this animal could be used as a relevant model for the human disease.

The similarities between the histopathological lesions in the gastric mucosa and the location of the $C$ pylori in the human and monkey tissues are striking. The only differences are the frequent correlation in patients of large numbers of polymorphonuclear leucocytes in the infiltrate with the presence of $C$ pylori and a possible relationship with peptic ulceration. ${ }^{1-5}$ Polymorphonuclear leucocytes were rarely seen in our series, and then only as isolated cells, nor was ulceration a feature, even at the histological level. It is probable, however, that the monkeys had been harbouring the infection for a considerable time and it is not surprising that polymorphonuclear leucocytes, as acute inflammatory cells, would not be present in the established, chronic infection. Marshall et al ${ }^{1.3}$ in a volunteer infection and gastroscopy experiment noted that polymorphonuclear leucocytes had gone by 14 days after infection and Morris and Nicholson reported in a similar study comparable results. ${ }^{14}$

The gastric Campylobacter-like organisms isolated 


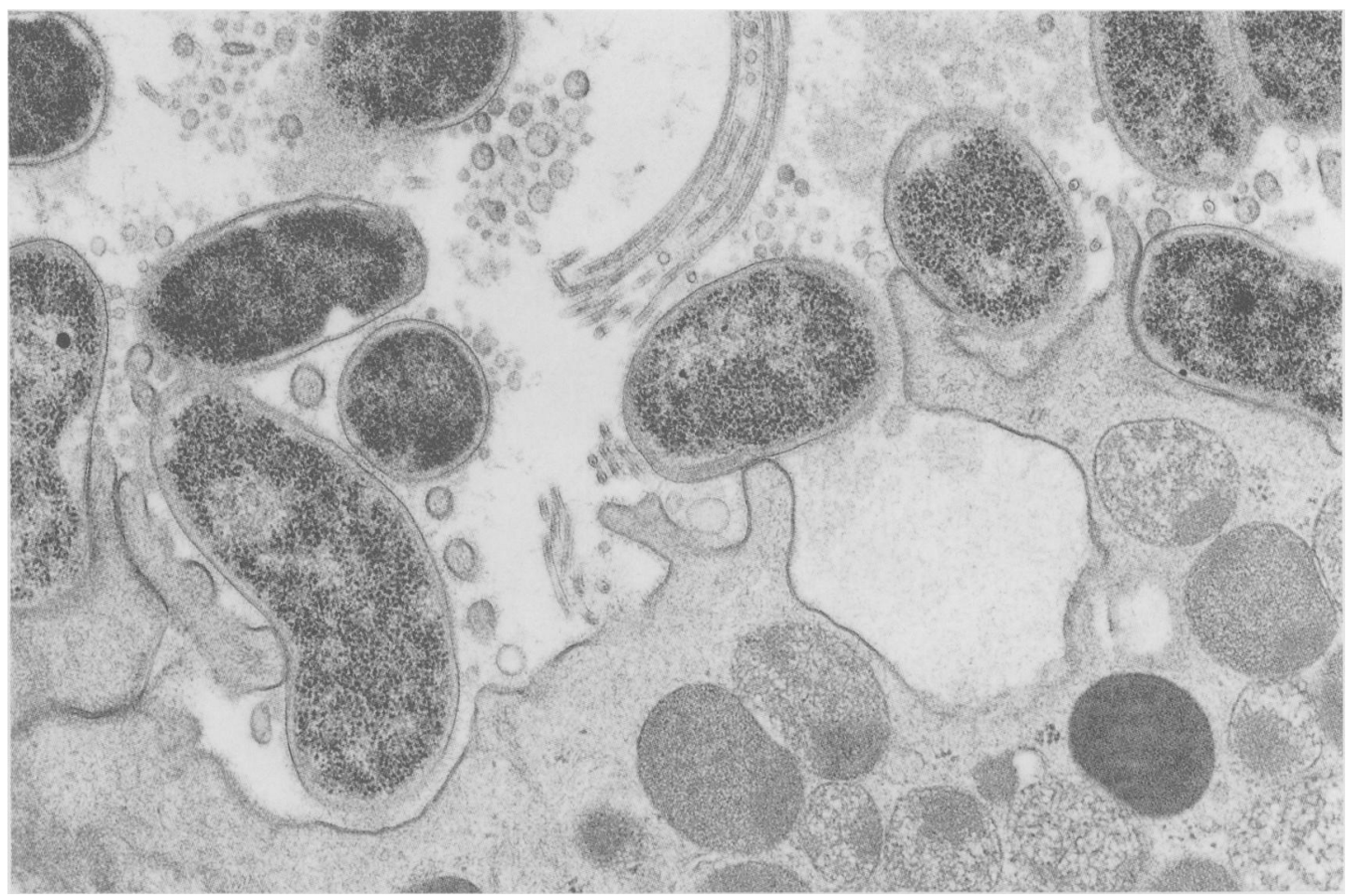

Fig. 6 Spiral bacteria on pit epithelial surface, with typical areas of attachment to the plasma membrane.

from the mucosa of the Rhesus monkeys were identical to the $C$ pylori isolated from the human antrum by all biochemical and morphological criteria, ${ }^{15}$ including transmission electron microscopy, SDS-PAGE total protein profiles, fatty acid analysis and immunoblotting with rabbit anti$C$ pylori antiserum and species-specific monoclonal antibodies." The evidence, therefore, justifies the classification of this organism as $C$ pylori henceforth. The existence of this organism in Rhesus monkeys indicates that $C$ pylori may be more widespread than previously thought and raises intriguing questions about its epidemiology.

The prevalence of chronic gastritis in this colony of Rhesus monkeys appears to be high $(80 \%)$, even though only a small proportion (around $3 \%$ ) was sampled. There was no evidence that the gastritis caused any clinical symptoms in the monkeys though it would not be possible to detect mild abdominal discomfort in animals kept under colony conditions. The source of the $C$ pylori infection is unknown, but because all ages of animal mix together there is great potential for spread. It is possible that very young animals acquire the infection from adults or from a common source in the environment and then harbour the bacteria for a long time. Alternatively, repeated

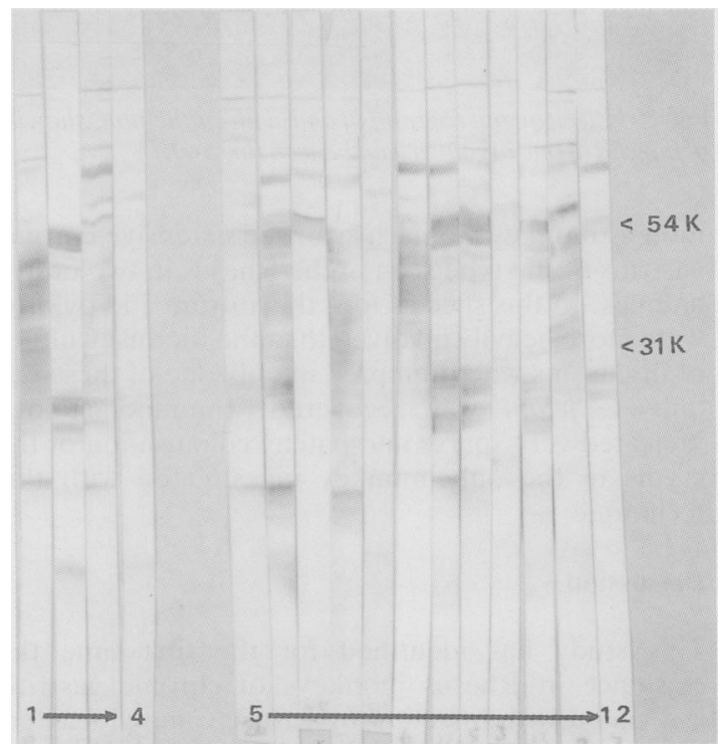

Fig. 7 Western blot of total protein profile of monkey gastric (ampylobacter-like organisms incubated with 1:10) dilution monkey sera. Tracks 1-4: sera from monkeys known to be infected. Tracks 5-16: sera from 12 other Rhesus monkeys not proven to be infected. 
clearance followed by reinfection may occur, although this seems unlikely as in man clearance of the organism is followed by recrudescence. ${ }^{16}$

Longterm infection evidently occurs in the presence of significant circulating anti-C pylori acid extract antibody responses in man, ${ }^{10}{ }^{17}$ where they have serodiagnostic value, and Rhesus monkeys. Unfortunately, the ELISA technique cannot be used to determine accurately the monkey antibody concentrations because the specificity of the peroxidase conjugated antiserum for monkey IgG is unknown. Certainly some of the monkeys had high antibody levels, however, and the specificity of these antibodies was confirmed by Western blotting and shown to be directed against a variety of $C$ pylori surface proteins. The antigenic profiles detected by the Rhesus monkey sera were very similar to that observed with sera from patients with gastritis. ${ }^{12}$ Interestingly, the presence of such antibodies does not appear to eliminate the infection, nor protect from recrudescence ${ }^{16}$. It is possible that the antigenic load, to which the gastric mucosa is exposed during $C$ pylori infections, initiates, or at least exacerbates, the local inflammatory responses leading to gastritis. Further studies on immunity, and particularly on immune mechanisms at this mucosal surface, would be important. This is one of the areas in which the monkey model might provide data for the situation in man.

The most important question is undoubtedly, does $C$ pylori directly cause the chronic gastritis? The evidence in man from numerous surveys, ${ }^{1-5}$ although strong, remains circumstantial. The volunteer experiments of Marshall et $a l^{13}$ and Morris and Nicholson $^{14}$ indicated that oral administration of $C$ pylori induces an acute inflammatory response with polymorphonuclear leucocyte infiltration, but of short duration. Experimental infection of young adult Rhesus monkeys with $C$ pylori cultures ${ }^{18}$ has been carried out after prophylactic dosing with metronidazole and cimetidine. Although mucosal infection was established and larger numbers of bacteria and more severe lesions resulted than in the natural disease, the time of the earliest autopsy stage (10 days) was unfortunately too late to ensure that substantial numbers of polymorphonuclear leucocytes would still be in the mucosa.

Although the association between $C$ pylori and chronic gastritis in the Rhesus monkey is strong the possibility still exists that the bacteria are secondary colonisers and the lesions are due to another cause, such as an unidentified viral infection. This seems unlikely and it may be significant that chronic gastritis was not found in 10 baboons, and $C$ pylori was not isolated from any of them. Chronic gastritis similar to that seen in the Rhesus was identified in two of five cynomolgus monkeys examined. Unfortunately, cultural examination was only undertaken on one of these, from which $C$ jejuni was isolated. The presence of $C$ jejuni in the stomach is thought to be the result of reflux from the duodenum at death. The swarming motility of this organism obscured any opportunity of isolating gastric Campylobacter-like organisms. It is therefore not confirmed that cynomolgus monkeys have a natural infection with $C$ pylori. The immunohistological staining, however, indicated a sparse and patchy distribution of $C$ pylori antigens in this animal. The fact that two animals did have gastritis suggests that this species also could be useful as an experimental model.

The ultrastructural features of $C$ pylori infection in Rhesus monkeys were very similar to those described in human biopsy material. ${ }^{5}$ In both hosts the $C$ pylori appear to cause ablation of microvilli and to form close attachments to the plasma membrane, often by means of cup-like depressions and points at which the membranes seem to fuse. These have been compared with attachment sites of enteropathogenic $E$ coli, termed adherence pedestals by some earlier workers. ${ }^{1920}$ In neither host has $C$ pylori been observed to penetrate epithelium or gland cells, nor was phagocytosis seen. If it should be proven that $C$ pylori plays an important causal role in gastritis then the readiness with which the Rhesus monkey can be infected experimentally, coupled with its natural susceptibility, make this an extremely valuable model for the elucidation of the mechanisms involved.

We are grateful for the skilled assistance of $\mathrm{Mr}$ A B Dowsett, Mrs Iris Francis, Mrs Emily Elphick, and Miss Diane Harwood.

\section{References}

1 Marshall BJ, Royce H, Annear DI, et al. Original isolation of Campylobacter pyloridis from human gastric mucosa. Microb Lett 1984; 25: 83-8.

2 Jones DM, Lessells AM, Eldridge J. Campylobacterlike organisms on the gastric mucosa: culture, histological and serological studies. J Clin Pathol 1984; 37: 1002-6.

3 Langenberg ML, Tytgat GNJ, Schipper MEI, Rietra PJGM, Zanen HC. Campylobacter-like organisms in the stomach of patients and healthy individuals. Lancet 1984; i: 1348.

4 Goodwin CS, McCulloch RK, Armstrong JA, Wee SH. Unusual cellular fatty acids and distinctive ultrastructure in a new spiral bacterium (Campylobacter pyloridis) from the human gastric mucosa. J Med Microbiol 1985; 19: 257-67.

5 Goodwin CS, Armstrong JA, Marshall BJ. Campylobacter pyloridis, gastritis and peptic ulceration. J Clin Pathol 1986; 39: 353-65. 
6 Newell DG. The production and characterisation of monoclonal antibodies directed against a species specific surface protein of $C$ pylori. In: Campylobacter IV. Proceedings of the IVth International Workshop on Campylobacter Infections. (In press) 1987.

7 Skirrow MB. Campylobacter enteritis: a new disease. $\mathrm{Br}$ Med J 1977; 2: 9-11.

8 Christensen WB. Urea decomposition as a means of differentiating proteins and paracolon cultures from each other and from Salmonella and Shigella. J Bact 1946; 52: 461-6.

9 Newell DG. Identification of the outer membrane proteins of Campylobacter pyloridis and antigenic crossreactivity between Campylobacter pyloridis and Campylobacter jejuni. J Gen Microbiol 1987; 183: 163-70.

10 Steer HW, Hawtin PR, Newell DG. An ELISA technique for the serodiagnosis of Campylobacter pyloridis infection in patients with gastritis and benign duodenal ulceration. Serodiagn Immunother 1987; 1: (In press).

11 Damian RT, Greene ND. The immunology of nonhuman primates. In: Pathology of Simian primates. Part 1. Basel: Karger, 1972: 342-79.

.12 Newell DG. Human serum antibody responses to the surface protein antigens of Campylobacter pyloridis. Serodiagn Immunother 1987; 1: 209-17.

13 Marshall BJ, Armstrong JA, McGechie DB, Glancy RJ. Attempt to fulfil Koch's postulates for pyloric Campylobacter. Med J Aust 1985; 142: 436-9.

14 Morris A, Nicholson G. Ingestion of Campylobacter pyloridis causes gastritis and raised fasting gastric $\mathrm{pH}$. Am J Gastroenterol 1987; 82: 192-9.

15 Newell DG, Baskerville A. Experimental and natural Campylobacter pylori infections in the Rhesus monkey. In: Campylobacter IV. Proceedings of the IVth International Workshop on Campylobacter Infections. (In press) 1987.

16 Langenberg W, Rauws EA, Widjojokusumo A, Tytgat GN, Zanen HC. Identification of Campylobacter pyloridis isolates by restriction endonuclease DNA analysis. J Clin Microbiol 1986; 24: 414-7.

17 Goodwin CS, Blincow E, Peterson G, et al. Enzymelinked immunosorbent assay for Campylobacter pyloridis: correlation with presence of $C$ pyloridis in the gastric mucosa. J Infect Dis 1987; 155: 488-94.

18 Baskerville A, Newell DG. Gastritis associated with experimental Campylobacter pylori infection in the Rhesus monkey: a model for the human infection? In: Campylobacter IV. Proceedings of the IVth International Workshop on Campylobacter Infections. (In press) 1987.

19 Takeuchi A, Inman LR, O'Hanley PD, Cantey JR, Lushbough WB. Scanning and transmission electron microscopic study of Escherichia coli 015 (RDEC-1) enteric infection in rabbits. Infect Immun 1978; 19: 686-94.

20 Cantey JR, Lushbough WB, Inman LR. Attachment of bacteria to intestinal epithelial cells in diarrhea caused by Escherichia coli strain RDEC-1 in the rabbit. Stages and role of capsule. J Infect Dis 1981; 143: 219-30. 